\title{
Sap flow of birch and Norway spruce during the European heat and drought in summer 2003
}

\author{
Gartner $^{a}$ K., Leitgeb ${ }^{a}$ E., Nadezhdina ${ }^{b}$ N., Englisch ${ }^{a}$ M. and Cermak ${ }^{b}$ J.
}

a Department of Forest Ecology and Soil, Research and Training Centre for Forests, Natural Hazards and Landscape, Seckendorff - Gudentweg 8, A-1131 Vienna, Austria

b Institute of Forest Ecology, Mendel Agricultural and Forestry University, Zemedelska 3, 61300 Brno, Czech Republic

\section{Introduction}

Climate change will have a large impact on all ecosystems of the earth. Especially forest ecosystems will be affected by the environmental changes. A very important issue in this context could be a possibly drastic restriction in the water supply of the trees and consequently a shift of forest communities. There are some indications that the frequency of extreme heat and drought periods over large parts of Europe will increase (IPCC 2001). The consequences of these changes for the water supply of the European forests are not known in detail. In Central Europe, where Norway spruce is often planted on unsuitable sites, spruce stands outside of its natural range could run into problems. In this study the differences in the effects of the drought 2003 on Norway spruce and birch, growing on heavy waterlogged soils were studied.

\section{Study site and methods}

The study site is located at $320 \mathrm{~m}$ a.s.l. near Fürstenfeld, a small town in the southeast of Austria. Mean annual temperature of this region is $8.8{ }^{\circ} \mathrm{C}$, mean annual precipitation is $765 \mathrm{~mm}$. The predominant soil type is a Stagnic Luvisol. The approximately 20 year old mixed stand mainly consists of birch (Betula pendula), Norway spruce (Picea abies Karst L.), German oak (Quercus robur) and trembling aspen (Populus tremula).

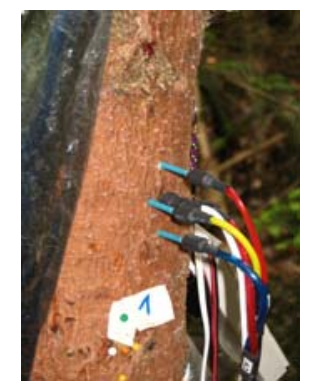

Figure 1:

Sap flow measurement by heat field deformation method (Nadezhdina et al. 1998).

Soil hydrology parameters were recorded continuously in three different soil horizons in two birch and in two spruce eco-groups. For the characterization of the different transpiration regime the sap flow of 12 birch and 11 spruce trees was measured, using the heat field deformation method (figure 1).

\section{Results}

June 2003 was very hot $\left(5^{\circ} \mathrm{C}\right.$ warmer than normal), which caused an intensive water consumption of the trees. However, the high water demand was satisfied by the soil water reservoir and by the actual precipitation. Therefore sap flow of both tree species was not restricted.

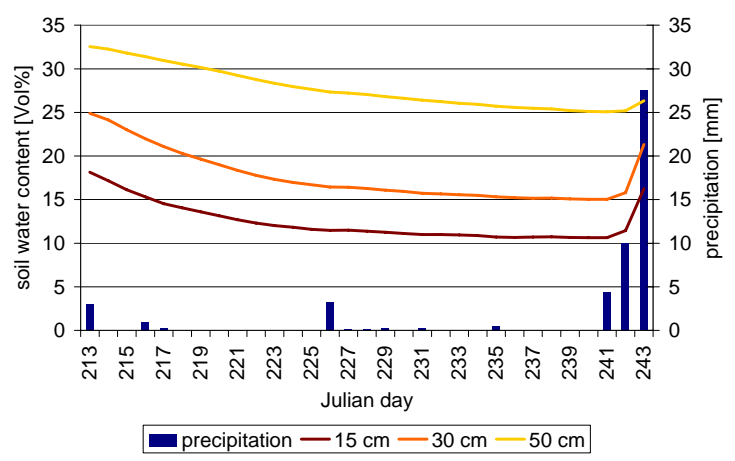

Figure 2: Mean soil water content in the depth of 15, 30 and $50 \mathrm{~cm}$ and daily precipitation sums in August 2003.
In July 2003 average climatic conditions prevailed but in August 2003 extreme weather conditions returned. It was hotter than in June and very dry. For this reason practically all soil water reserves in the top soil were exhausted (figure 2). In the last week of August no change in soil water content occurred any more in the upper part of the soil until heavy rainfall terminated the very hot period.

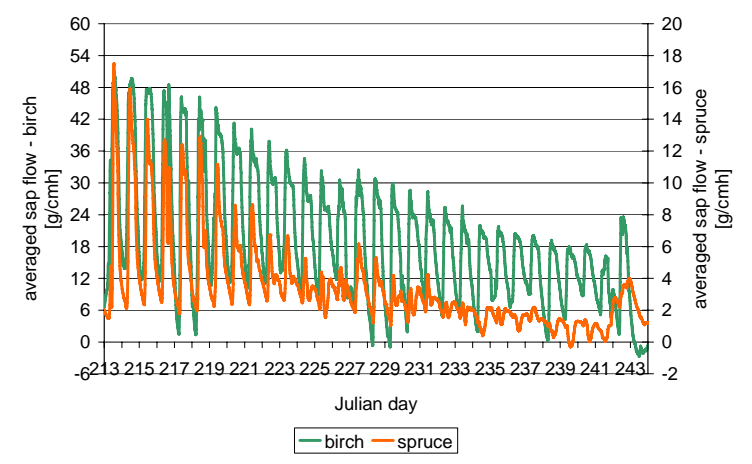

Figure 3: Averaged sap flow for 10 birch (green line) and 8 spruce trees (orange line) in August 2003.

Hence the trees had to restrict their transpiration. In figure 3 the averaged sap flow of birch and spruce trees in August 2003 is compared. It is clearly visible that the spruce trees reduced their sap flow much more than the birch trees. (a)

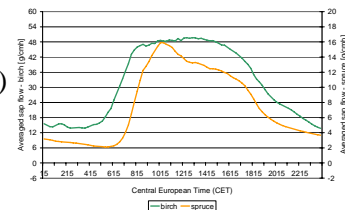

(c)

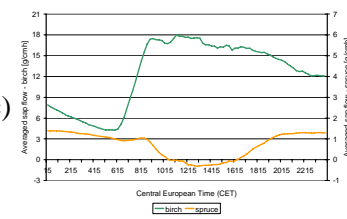

(b)

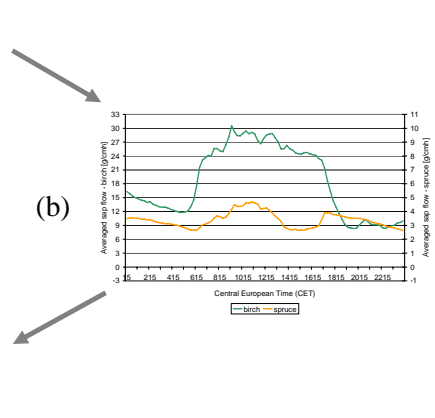

Figure 4: Mean daily variation of sap flow for 10 birch (green line) and 8 spruce trees (orange line) for three selected days: (a) 2003-08-02, (b) 2003-08-14 and (c) 2003-08-27.

The stronger reaction of the spruce trees to drought stress in comparison to the birch trees is also visible in the daily variation of sap flow. Noon depressions could be recognized in the sap flow of most Norway spruce trees, which got increasingly pronounced with the duration of the drought episode (figure 4). In contrast the sap flow of the birch trees hardly showed this phenomenon.

\section{Conclusion}

The drought in summer 2003 showed different effects on the sap flow of birch and spruce. As Norway spruce with its shallow rooting system uses mainly the soil water from the upper soil, these trees showed a stronger restriction in sap flow than birch. The reaction of birch in the daily pattern of sap flow was obviously less distinctive than that of spruce.

So the handicap of Norway spruce on ecological sensitive soils during such extreme weather conditions in comparison to a pioneer species like birch became clearly visible.

\section{Reference}

IPCC (2001): Climate Change 2001 (Vol. 1-3). Intergovernmental Panel on Climatic Change. Cambridge University Press, Cambridge.

Nadezhdina N., Cermak J. and Nadezhdin V. (1998): Heat field deformation method for sap flow measurements. In: Proc. 4th. Intern. Workshop on Measuring Sap Flow in Intact Plants. Eds. J. Cermak and N. Nadezhdina. IUFRO Publications. Publ. House, Mendel Univ. Brno, Czech Republic, pp. 72-92. 